\title{
Hyperspectral imaging, spectrofluorimetry, FORS and XRF for the non-invasive study of medieval miniatures materials
}

Aurélie Mounier ${ }^{1 *}$, Gwénaëlle Le Bourdon ${ }^{2}$, Christian Aupetit ${ }^{2}$, Colette Belin ${ }^{2}$, Laurent Servant ${ }^{2}$, Sylvain Lazare ${ }^{2}$, Yannick Lefrais ${ }^{1}$ and Floréal Daniel ${ }^{1}$

\begin{abstract}
Background: Illuminated manuscripts are complex multi-layer and multi-material objects. To this difficulty, from the analytical point of view, is added the impossibility of removing samples from these paintings for the study of their materials and techniques. There are relatively few analytical methods that satisfy these constraints as the availability of non-invasive techniques adapted to painted manuscripts is limited and mainly focused on the characterization of inorganic compounds. In the context of a research project on the analytical study of the forty miniatures in the Marcadé collection (Treasury of the Saint-André Cathedral of Bordeaux, XIII to XVI century), the potential of two non-invasive methods, hyperspectral imaging (HSI) and spectrofluorimetry is explored.
\end{abstract}

Results: The methodological development of these techniques as well as preliminary tests on miniatures recreated according to medieval recipes and materials, allowed the validation of the analytical parameters and the creation of a database of reference spectra (parchments, pigments, binders). Hyperspectral imaging associates reflectance spectra with each pixel of the image and treats the signal received in various wavelengths. The characteristics of the spectral signal in VIS range or NIR are used to get an identification and a localization of the components. It allows the study of the entire image and offers lots of ways to work: comparison of spectra, mapping, principal component analyses and false color images. Spectrofluorimetry is a sensitive method which gives information on fluorescent organic compounds under UV or visible light. Emission and excitation spectra of five red pigments in binding media have been collected. These methods were compared with X-ray fluorescence spectrometry for the qualitative analysis and mapping of the inorganic elements in a facsimile which had been purposely reproduced by an illumination painter who worked with original medieval recipes for the sake of developing the present study.

Conclusions: The combination of all these techniques allows good identification of all the materials used on an illuminated manuscript. The pertinent selection of the wavelengths used with the HSI system and a preliminary database and study of materials under UV and white light is described in this paper.

Keywords: Hyperspectral imaging, Spectrofluorimetry, Reflectance spectra, Pigments, Miniatures collection

\footnotetext{
* Correspondence: mounieraurelie33@yahoo.fr

IIRAMAT - CRPAA, Institut de Recherche sur les Archéomatériaux, UMR CNRS 5060, Centre de Recherche en Physique Appliquée à l'Archéologie, Université de Bordeaux 3, Maison de l'archéologie, Esplanade des Antilles, 33607 Pessac, France

Full list of author information is available at the end of the article
}

\section{Chemistry Central}

(c) 2014 Mounier et al.; licensee Chemistry Central Ltd. This is an Open Access article distributed under the terms of the Creative Commons Attribution License (http://creativecommons.org/licenses/by/4.0), which permits unrestricted use, distribution, and reproduction in any medium, provided the original work is properly credited. The Creative Commons Public Domain Dedication waiver (http://creativecommons.org/publicdomain/zero/1.0/) applies to the data made available in this article, unless otherwise stated. 


\section{Introduction}

This paper is a preliminary methodological study and implementation of non-destructive techniques for the study of fragile objects for which sampling is prohibited. Eventually, the findings will be used to examine the illuminations of the Marcadé collection (treasury of the Cathedral of Bordeaux).

The Marcadé collection consists of a group of fortytwo illuminations, among other objects (paintings, sculptures, liturgical vestments and silver objects). It was given to the Cathedral of Bordeaux by canon Marcadé in 1947. These illuminations, little studied so far, will be exhibited in 2015 in the cathedral, in a room specially designed for this collection.

Restoration actions have been undertaken and a threeyear project $\mathrm{t}^{\mathrm{a}}$ started with the goal of completing the historical, stylistic and physicochemical analysis of this set of miniatures dating from the XIII to the XVI century. The project brings together experts from different disciplines (archaeometrists, physical chemists and conservators) providing a platform for the exchange of knowledge and practices implemented around these particular types of heritage objects. The stylistic study of the illuminated miniatures, which is a prerequisite for a study of the collection, has revealed some pertinent features of the objects such as approximate dates and likely geographic sources (France, Italy, Spain, Germany and the Netherlands).

Non-destructive methods that do not require contact with the object were selected with the main ones being hyperspectral imaging, fiber optic reflectance spectroscopy (FORS) and fluorimetry. Applying a combination of art historical and analytical methods to this collection enhances our knowledge of the physical objects, helps to identify the sources and any changes in techniques of illumination in medieval times, and guides the choice of restoration treatments.

To reach this main goal, a second preliminary objective was established, which consisted of defining a specific methodology based on the spectrometric analysis of the works. The project thus aims at developing a methodology more generally applicable to the study of the collections of museums (paintings, pastels, graphic art) which are too seldom studied from a technical point of view because of the double constraint connected to the impossibility of transporting the objects to the laboratory and of performing invasive sampling.

In addition to common preliminary methods of examination commonly used on paintings such as infrared reflectography (IRR) or inspection under ultraviolet illumination, hyperspectral imagery allows for the recognition of particular zones of interest (gildings, overpainting), the study of the preparatory underdrawing, the identification of pigments and the acquisition of an overview of the entire object, thus ensuring the relevance of the sampling [1-3].
If the methods of analysis currently available often allow a characterization of pigments, at present information concerning the organic materials (binders, glues, resins, etc.) is difficult to obtain without using sampling, which turns out to be totally excluded when studying medieval manuscripts. The solution to this difficulty lies in the development of in-situ spectrometric analysis techniques that are well adapted to this type of cultural heritage object and therefore highly appreciated. Some methods such as fluorimetry, Raman or IR spectrometry are effective in this respect but require an adaptation of the laboratory devices to the constraints of the in-situ analysis of manuscript paintings.

Non-destructive analysis methods such as Raman spectrometry have been widely used for the characterization of pigments [4,5]. Some of these methods (diffuse reflectance spectrometry, X-rays fluorescence spectrometry) are portable and allow in situ analysis while protecting the integrity of ancient objects (characterization of the materials of the color, elementary analysis of metallic layers) [6-10].

Infrared spectrometry and spectrofluorimetry allow for the identification of organic materials. Indeed, numerous papers demonstrate the utility of infrared spectrometric analysis of pigments and ink [11], binders like gum arabic [12] and egg white [13] as well as of supports such as parchment [14]. Publications containing reference spectra show that they present characteristics allowing the identification of the organic components of illuminations.

The aim of this paper is to combine various techniques for the discrimination, identification and mapping of materials commonly and mostly used on medieval manuscripts. This paper focuses on five red pigments: three inorganic (red lead, cinnabar, red ochre) and two organic (cochineal and brazil wood) mixed with different binders (gum arabic and rabbit skin glue). We tried to show how point analysis and global imaging are complementary methods, but mainly how the former techniques are a preliminary approach and essential for the understanding and treatment of results obtained with the latter methods such as hyperspectral imaging.

\section{Experimental}

Experimentation on reference test materials is necessary to validate the analytical techniques and to identify the optimum parameters for the analysis of the materials of illuminations before applying them to the Marcadé collection.

- Ancient materials and illumination techniques are cited in the bibliography [15-17]. Five red pigments (red lead, cinnabar, red ochre, brazil wood and cochineal) were studied with FORS and fluorimetry, alone and mixed with the two most commonly used organic binders (gum arabic and rabbit skin glue). 
Nine other pigments were also studied alone or mixed with gum arabic with FORS and HSI: lead tin yellow (type II), orpiment, lapis-lazuli, azurite, Egyptian blue, malachite, lead white, calcite and carbon black.

- Binder preparation: gum arabic was previously ground in a mortar: one part in weight of gum arabic for two parts of water. The gum was placed in a nylon stocking and soaked in deionized water for 5 hours so that the solution is melted and fluid enough to be placed on the quartz plate $[17,18]$. For the rabbit skin glue, one part was mixed with two parts of deionized water and then allowed to warm in a water bath at a temperature below $40^{\circ} \mathrm{C}$ to avoid denaturing the collagen [18].

- Pigments preparation: Pigments were supplied by Ôkhra society. The inorganic pigments as red lead $\left(\mathrm{Pb}_{3} \mathrm{O}_{4}\right)$, cinnabar $(\mathrm{HgS})$ and red ochre $\left(\mathrm{Fe}_{2} \mathrm{O}_{3}\right)$ were just mixed with the binder and applied on glass or quartz slides. The two organic pigments (cochineal and brazil wood) were prepared in the laboratory according to ancient techniques.

- The preparation of cochineal takes about 3 hours. $10 \mathrm{~g}$ of cochineal was crushed in an agate mortar and soaked in 1/8 liter of sodium ash wood for

2 hours. The solution was filtered and boiled. $1 / 8$ liter of a saturated solution of alum in demineralized water was then added to the mixture off the heat. The mixture was passed through a filter (gauze pad) and then left to dry in the shade (recipe taken from "the manuscript of Padua” (XVII century) [19]).

- Brazil wood requires three days of preparation. The wood chips were first pulverized using a kitchen blender. $4.3 \mathrm{~g}$ were placed in a jar and then covered with an egg white. The mixture was left to macerate for two days. $1.65 \mathrm{~g}$ of powdered alum $+0.86 \mathrm{~g}$ of brazil wood were mixed and then melted in gummed water. This mixture was poured into the jar on brazil wood and egg white, and left to macerate again for one day. Everything was passed through gauze and allowed to dry in a wide-bottomed container (this recipe is taken from two treatises: Illuminandi De Arte, XIV century [17] p. 65 and Jehan Le Begue, Experimenta of coloribus pro illuminando libro, XV century, p $54 \$ 16)$ [20].

- The five red pigments mixed with the two binders were prepared on quartz plates for the study of fluorescence to avoid any contribution from the substrate. Two quartz plates were coated with preparations to measure the analysis reproducibility. The fourteen pigments mixed with the gum arabic were deposited on glass plates for the FORS and HSI analyses.
- A facsimile of a medieval miniature $\mathrm{e}^{\mathrm{b}}$ was made according to the medieval techniques on a sheepskin parchment by an illuminator (Marlier's workshop) for the XRF and HSI analyses. The painting measures about $7 \times 8 \mathrm{~cm}$. Only one face of the parchment is painted. Nine pigments were used: azurite, lapis-lazuli, cinnabar, cochineal, orpiment, yellow ochre, lead white, carbon black and gold shell. Two preparation binders were carried out: glue sturgeon swim bladder and gum arabic mixed with egg white and honey.

The painting to be analyzed by XRF was positioned in a holder made of two rigid paper cards, with the top one containing a window $(2 \times 2 \mathrm{~cm})$ in order to avoid distortion of the parchment caused by variations in ambient temperature or relative humidity.

\section{Methods}

\section{Fiber Optics Reflectance Spectroscopy (FORS)}

FORS analysis was performed with a system marketed by Ocean Optics composed of a HL2000 tungsten light source (20-watt bulb) optimized for the VIS-NIR (360$2000 \mathrm{~nm}$ ). A FVA-UV variable attenuator is added to control the light intensity. Fiber optic reflection/backscattering probes are used for measuring specular or diffuse reflectance and fluorescence. Six illumination fibers are set around one read fiber of $200 \mu \mathrm{m}$ diameter. The $\mathrm{RPH}-1$ aluminum probe holder allows us to position the fiber with an angle of $45^{\circ}$ or $90^{\circ}$. Data were carried out using R software and curves with Excel.

\section{Ray Fluorescence (XRF)}

The $\mathrm{X}$ ray spectrometry fluorescence device (SEIKO, SEA 6000VX) has an X-ray tube of $50 \mathrm{kV}$ with a rhodium target. The detector SDD type $\left(50 \mathrm{~mm}^{2}\right.$; resolution $155 \mathrm{eV}$ ) is cooled by Peltier. It provided a He flux for detecting light elements and global detection from $\mathrm{Na}$ to $\mathrm{U}$. It is equipped with four sizes of probe collimators $(3 \times 3 \mathrm{~mm} / 1.2 \times 1.2 \mathrm{~mm} / 0.5 \times 0.5 \mathrm{~mm}$ and $0.2 \times 0.2 \mathrm{~mm})$. The specimen holder is motorized and larger $(270 \times$ $220 \times 150 \mathrm{~mm}, 5 \mathrm{~kg}$ max.). The repositioning accuracy is about $5 \mu \mathrm{m}$. It permits qualitative and quantitative analysis (with standards) and qualitative cartography.

Qualitative analysis and cartography have been done on a facsimile of a medieval painting. For these analyses, we used 15 and $50 \mathrm{kV}$. The image size is $480 \times 500$ pixels $(=50 \mu \mathrm{m} /$ pixel $)$ with a collimator at $0.2 \times 0.2 \mathrm{~mm}$. The time per pixel is $10 \mathrm{~ms}$ and 3 accumulations were used. The time required for a mapping is about 2 hours.

\section{Spectrofluorimetry}

Fluorescence measurements were performed using a JobinYvon Fluorolog SPEX 212 spectrofluorimeter equipped 
with a double monochromator on both the excitation and emission beams. The excitation lamp is a $450 \mathrm{~W}$ high pressure xenon lamp. A thermoelectrically cooled photomultiplier (Hamamatsu R928) is used for the signal detection, using the photon counting mode. Fluorescence signals are expressed in "counts per second" (cps). Data acquisition and data processing were computer controlled (SpectrAcq Datamax runned by the Grams/32 software). Both excitation and emission spectra (recorded with $4 \mathrm{~nm}$ bandwidth) were corrected for instrumental factors. The measurements are made in mode "front face". The emitted light is collected according to an angle of $22.5^{\circ}$ with respect to the excitation beam.

\section{Hyperspectral imaging (HSI)}

The hyperspectral system is provided by LOT-Quantum Design Sarl and developed by SPECIM (Finland). The CCD camera has a $1600 \times 840$ pixels resolution; the entrance slit is $30 \mu \mathrm{m}$ wide. The focal length of the lens is $23 \mathrm{~mm}$. The translation system measures $1.30 \mathrm{~m}$ and was controlled by IDAQ software. The hyperspectral system works horizontally or vertically. Two halogen lamps illuminate the sample. A Prophotonix Cobra slim UV line scan illuminator of $30 \mathrm{~cm}$ also allows excitation at $365 \mathrm{~nm}$ for UV fluorescence imaging. The treatment of the data cube is performed with ENVI 5.0 + IDL software. For the study of illuminations, the experimental conditions are: working distance of $31.5 \mathrm{~cm}$, scan speed at $3 \mathrm{~mm} / \mathrm{s}$ and exposure time at $25 \mathrm{~ms}$.

\section{Results and discussion FORS-DRS}

Non-invasive techniques such as the Fiber Optics Reflectance Spectroscopy (FORS) technique and Diffuse Reflectance Spectrometry (DRS) have been used for the study of illuminations for twenty years and allow the identification and discrimination of pigments.

As all FORS spectra of the five red pigments are different and characteristic (Figure 1), the inflection points can be used to characterize each pigment. For example, the points at $550 \mathrm{~nm}$ and $600 \mathrm{~nm}$ are characteristic of red lead. We must also consider the shape of the curve (e.g., convex or concave).

Principal Component Analysis (PCA) also allows discrimination of spectra. The spectra must first be normalized to diminish the influence of intensity variations. Spectral data below $500 \mathrm{~nm}$ were not included since they have no influence for red pigments.

The points which characterize each red pigment on the PCA plot are well separated (Figure 2). So we are able to assume that pigment identification is possible. If the spectrum of an unknown pigment is added to the data, it should be close to the reference pigment.

FORS is of great interest for the pigments identification, but it is a point technique and does not permit imagery.

\section{$\mathrm{X}$-ray fluorescence (XRF)}

$\mathrm{X}$-ray fluorescence spectroscopy allows the identification of some pigments with characteristic elements and offers the possibility of elemental mapping. XRF offers the possibility of mapping and localizing pigments, thereby

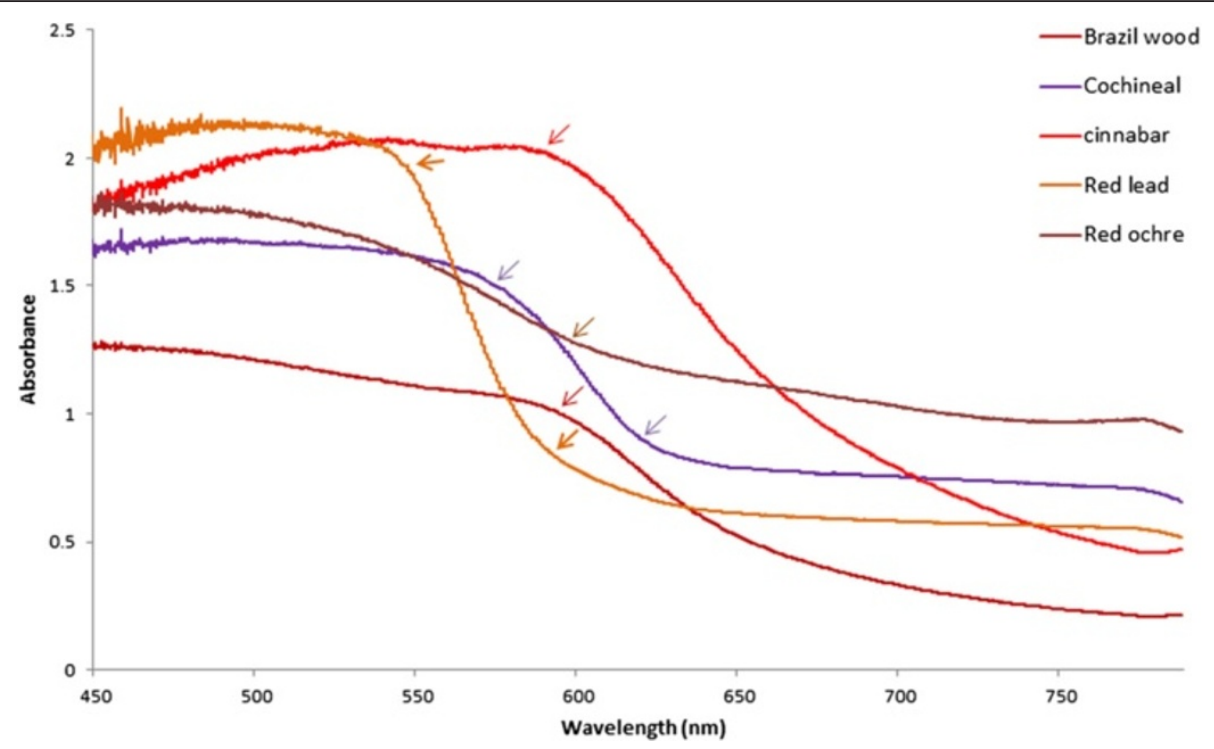

Figure 1 DRS-FORS spectra of the five red pigments. All the curves are different and inflection points are characteristic of each pigment. For example, points at 550 and $600 \mathrm{~nm}$ are specific to red lead. 


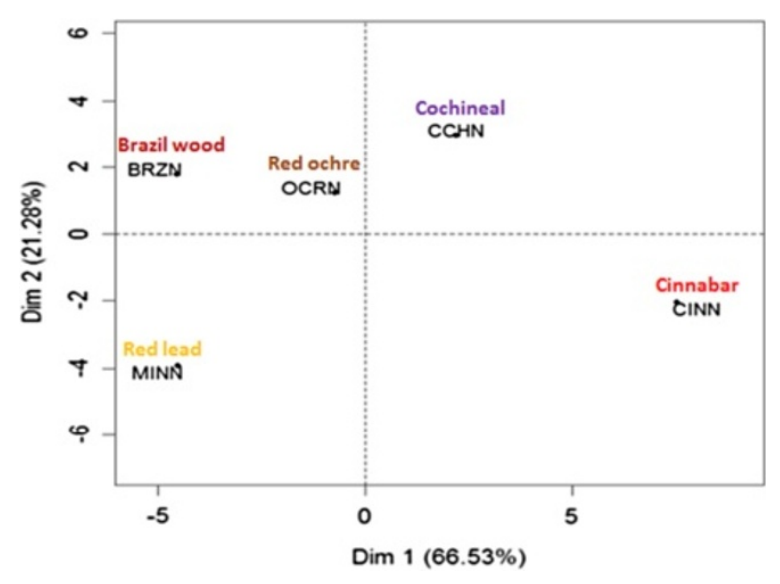

Figure 2 Principal Component Analysis of the five red pigments from DRS-FORS spectra. All the five pigments are well separated. This treatment allows the identification and separation of red pigments.

producing an elemental map (Figure 3). The presence of copper on blue zones is attributed to azurite $\left(\mathrm{Cu}_{3}\left(\mathrm{CO}_{3}\right)_{2}\right.$ $\left.(\mathrm{OH})_{2}\right)$; lead in white zones to lead white $\left(\mathrm{PbCO}_{3}\right)_{2} \cdot \mathrm{Pb}$ $(\mathrm{OH})_{2}$; gold for the gilding of the background of the scene; sulfur and mercury for cinnabar ( $\mathrm{HgS}$ ) for the red halo; and arsenic for the yellow pigment orpiment $\left(\mathrm{As}_{2} \mathrm{~S}_{3}\right)$.

XRF allows for reliable identification of some inorganic compounds. Though it is difficult with this technique to distinguish between the blue pigment azurite and Egyptian blue based on the presence of copper, hyperspectral imaging can be used to readily tell these pigments apart (see below). Also, the presence of lead corresponds to lead white as well as to red lead, which may make it difficult to identify which pigments are present depending on the color of the analyzed area. Organic pigments (cochineal, brazil wood) or binders are not recognizable by this technique.

\section{Spectrofluorimetry}

Spectrofluorimetry, known for the study of fluorescence binders or organic pigment, has also proved to be a technique for the identification and discrimination of inorganic pigments [21,22].

The aim of these measurements is to evaluate the potential of spectrofluorimetry for the discrimination between the five red pigments and to collect detailed spectroscopic information useful for further hyperspectral imaging investigations.

This paper focuses on the results obtained with the $366 \mathrm{~nm}$ excitation wavelength $\left(\lambda_{\text {exc }}\right)$ which proved to be appropriate for the characterization of the binding media and pigments under consideration. This excitation wavelength is widely used and has been validated in previous studies [23-27].

The emission spectra acquired on the different pigments mixed with gum arabic as binder are presented in Figure 4 and the spectra collected on samples prepared with rabbit skin glue in Figure 5. The spectra show fluorescence emission bands in two spectral regions. Emission bands from 380 to $540 \mathrm{~nm}$ are related to the binder, and features from 540 to $700 \mathrm{~nm}$ are characteristic of the pigments.

The emission spectra of the un-pigmented films present emission features in the region of 380-540 nm. Both gum arabic and rabbit skin glue present broad bands centered at $440 \mathrm{~nm}\left(\lambda_{\text {exc }}=366 \mathrm{~nm}\right)$ that originate from multiple fluorophores. Indeed, gum arabic is a complex mixture mainly made of carbohydrates, uronic acids and proteins. In addition, chemical analyses revealed the presence of residues of tryptophan and phenolic compounds [28], both also being contributors to fluorescence emission. Upon excitation at $366 \mathrm{~nm}$, the fluorescence from the amino acids of proteins is not excited and the observed feature can be ascribed to the degradation products of the amino acids (phenylalanine, tyrosine and tryptophan)

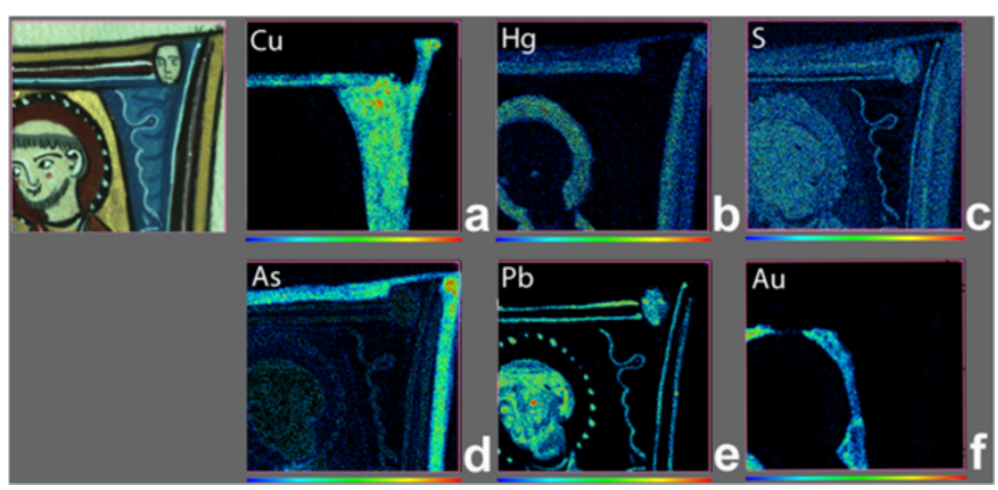

Figure 3 XRF cartography of elements present on a little zone of the image. With elements, we can identify the pigments used for the illumination. The analysis zone corresponds to Saint Peter's head: copper (a) in blue pigments (azurite); mercury (b) in red pigments (cinnabar); sulfur (c) associated with mercury for the red pigments (cinnabar) and with arsenic (d) for the yellow one (orpiment); lead (e) in white pigments composed of lead white; Gold (f) is present in the gilding zone, in the background of the scene. 


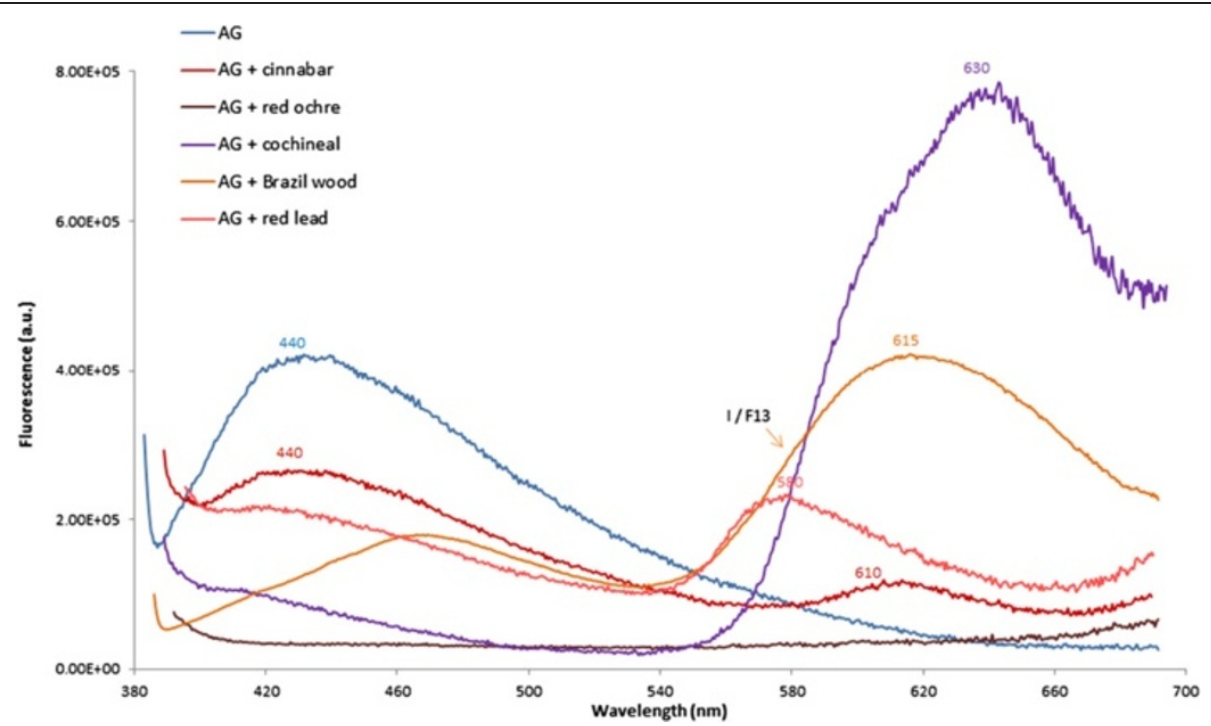

Figure 4 Fluorescence emission spectra $\left(\lambda_{\text {exc }}=366 \mathrm{~nm}\right.$ ) from films of gum arabic and gum arabic mixed with the five red pigments. Gum arabic shows emission at about $440 \mathrm{~nm}$. Red lead presents additional emission at $580 \mathrm{~nm}$, cinnabar at $610 \mathrm{~nm}$, cochineal at $630 \mathrm{~nm}$ and brazil wood around $615 \mathrm{~nm}$ (intensity divided by factor 13). No fluorescence is observed with red ochre.

and to compounds formed between sugars and reducing proteins in the Maillard reaction [24,29-31]. When adding the pigments, changes are observed in the intensity and maximum position of the fluorescence of the gum arabic, due to the interactions between the binder and pigments. The fluorescence from rabbit skin glue can also be attributed to the products of photo-oxidation, combinations and modifications of amino acids from proteins found in collagen (tryptophan-free) [32-35] and it is also influenced by the pigment-binder interactions.

Most of the emission spectra acquired from the films made of pigments mixed with the binding media exhibit additional characteristic bands in the region of 540 to $700 \mathrm{~nm}$. Whatever the binder (gum arabic or rabbit skin

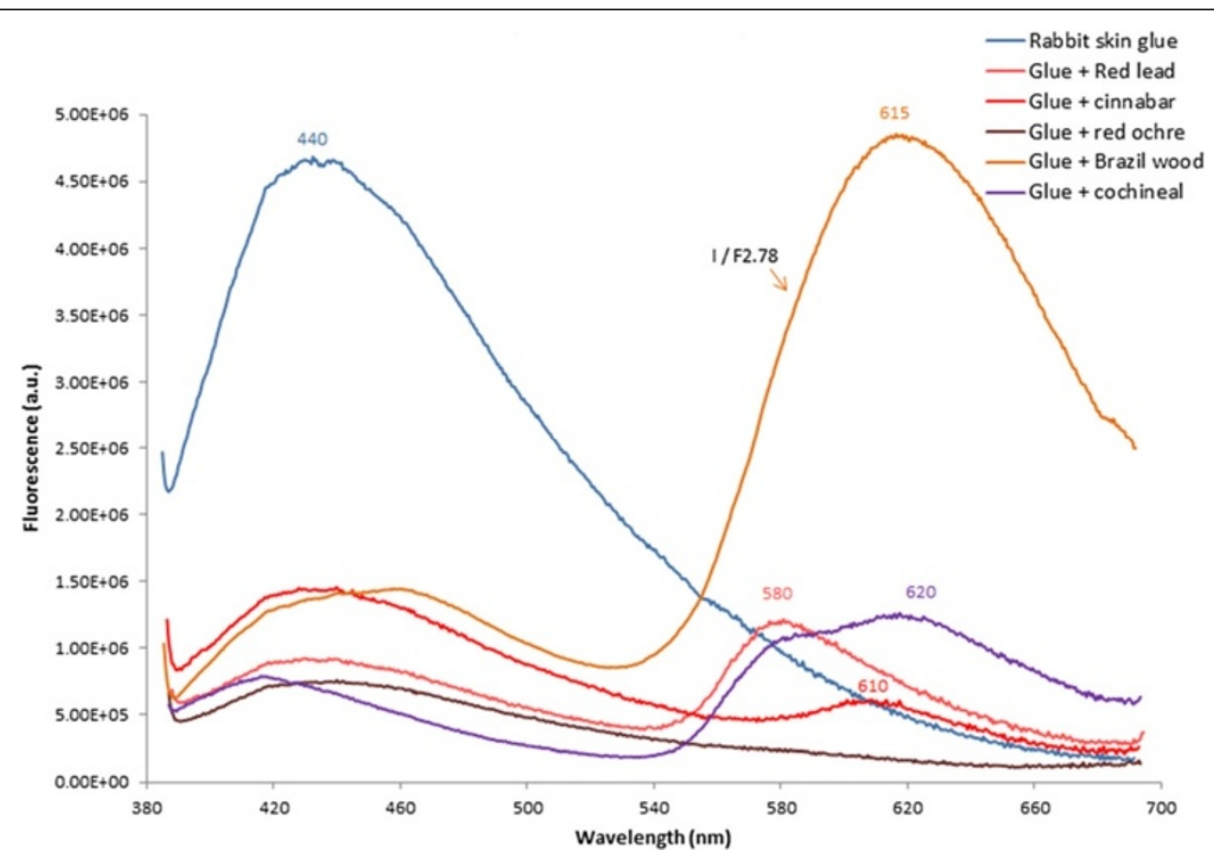

Figure 5 Fluorescence emission spectra $\left(\lambda_{\mathrm{exc}}=366 \mathrm{~nm}\right)$ from films of rabbit skin glue and rabbit skin glue mixed with the five red pigments. Rabbit skin glue presents emission at about $440 \mathrm{~nm}$. Red lead shows additional emission maximum at $580 \mathrm{~nm}$, cinnabar at $610 \mathrm{~nm}$, cochineal at $620 \mathrm{~nm}$ and brazil wood around $615 \mathrm{~nm}$ (intensity divided by factor 2.78). Red ochre shows very weak fluorescence. 
glue), the wavelength of this emission band is observed at the same position.

Mixed with both binders, cinnabar ( $\mathrm{HgS})$ shows a second fluorescence emission with a maximum wavelength at $610 \mathrm{~nm}$ which corresponds to the semiconductor $\mathrm{HgS}$ $[36,37]$. Red lead $\left(\mathrm{Pb}_{3} \mathrm{O}_{4}\right)$ presents a band at $580 \mathrm{~nm}$ that could be associated with irregularities in the crystal structure or presence of impurities [25].

Regarding the organic pigments, a broad band is observed at $615 \mathrm{~nm}$ for the films containing brazil wood and at a longer wavelength $(620-630 \mathrm{~nm})$ for cochineal. In the case of cochineal, this emission can be attributed to its fluorescent anthraquinone based constituents (predominantly carminic, kermesic and flavokermesic acids, and also other minor anthraquinones recently identified $[38,39])$. Several fluorimetric studies of anthraquinoid colorants have been performed, such as on purpurin and alizarin currently used as madder lake $[22,40]$.

Red ochre $\left(\mathrm{Fe}_{2} \mathrm{O}_{3}\right)$ does not show any additional fluorescence emission. In case of the mixture with gum arabic, a decrease is observed in the fluorescence attributed to the binding medium that could be explained by a quenching effect [41].

In order to confirm the attribution of the emission bands observed in the 540-700 $\mathrm{nm}$ region to the pigment, acquisition of excitation spectra was performed in addition to the emission spectra. Excitation spectra were acquired from the films made of each pigment-binder mixture (Figure 6) and were compared to the absorption spectra conducted on the pigment powders without a binder (Figure 7). For each pigment, the observation wavelength used to acquire the excitation spectrum corresponds to the observed peak position of the maximum of fluorescence emission. The excitation spectra carried out on cochineal and brazil wood films are similar to the absorption spectra measured from the pigments powders, even if some slight differences can be observed and explained by the nature of the pigments (mixtures that can contain absorbing but not fluorescing species). However, this confirms that the observed fluorescence peaks in the 540-700 nm mainly originate from the red pigments.

Spectrofluorimetry proves to be an effective tool for the characterization and differentiation of these red pigments whatever the binder. The technique provides characteristic emission wavelengths that can directly be used for pigment mapping with hyperspectral camera under UV light.

\section{Hyperspectral imaging under halogen light}

Hyperspectral imaging was done on the facsimile reproduced using ancient medieval techniques and on a range of pigments commonly used in medieval manuscripts, such as lead white, orpiment, azurite or red lead. An RGB image is obtained ( $R=700 \mathrm{~nm} ; \mathrm{G}=550 \mathrm{~nm} ; \mathrm{B}=448 \mathrm{~nm}$ ) (Figure 8, left) with a matrix of reflectance spectra (400 to $1000 \mathrm{~nm}$ ) associated with each pixel of the image.

An infrared false color (IRFC) image is also obtained by selecting one infrared band for the red band, and two others in the visible range for green and blue band $(\mathrm{R} \rightarrow$ $900 \mathrm{~nm} ; \mathrm{G} \rightarrow 650 \mathrm{~nm} ; \mathrm{B} \rightarrow 550 \mathrm{~nm})$. The comparison of

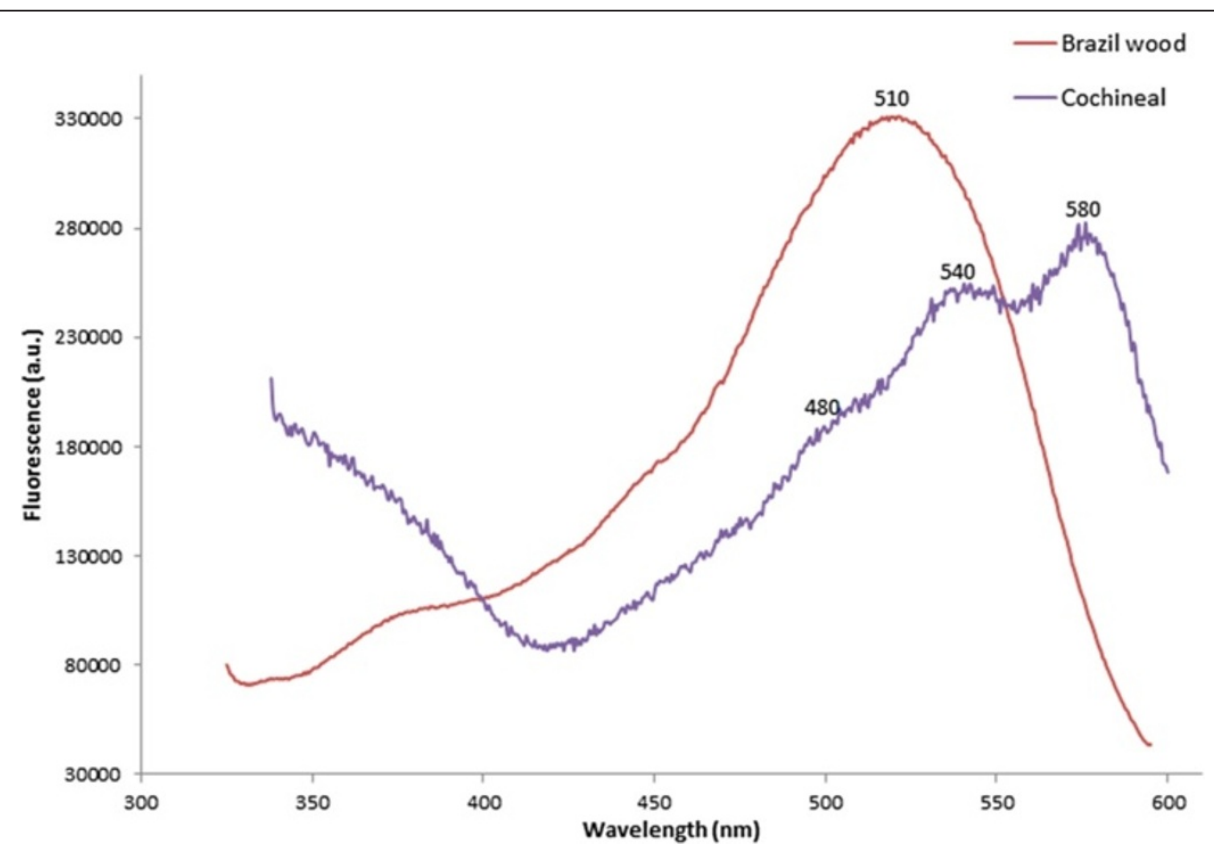

Figure 6 Fluorescence excitation spectra from films of gum arabic mixed with brazil wood and cochineal. (Observation wavelengths $\lambda_{\text {obs }}=615 \mathrm{~nm}$ for brazil wood and $\lambda_{\text {obs }}=640 \mathrm{~nm}$ for cochineal). 


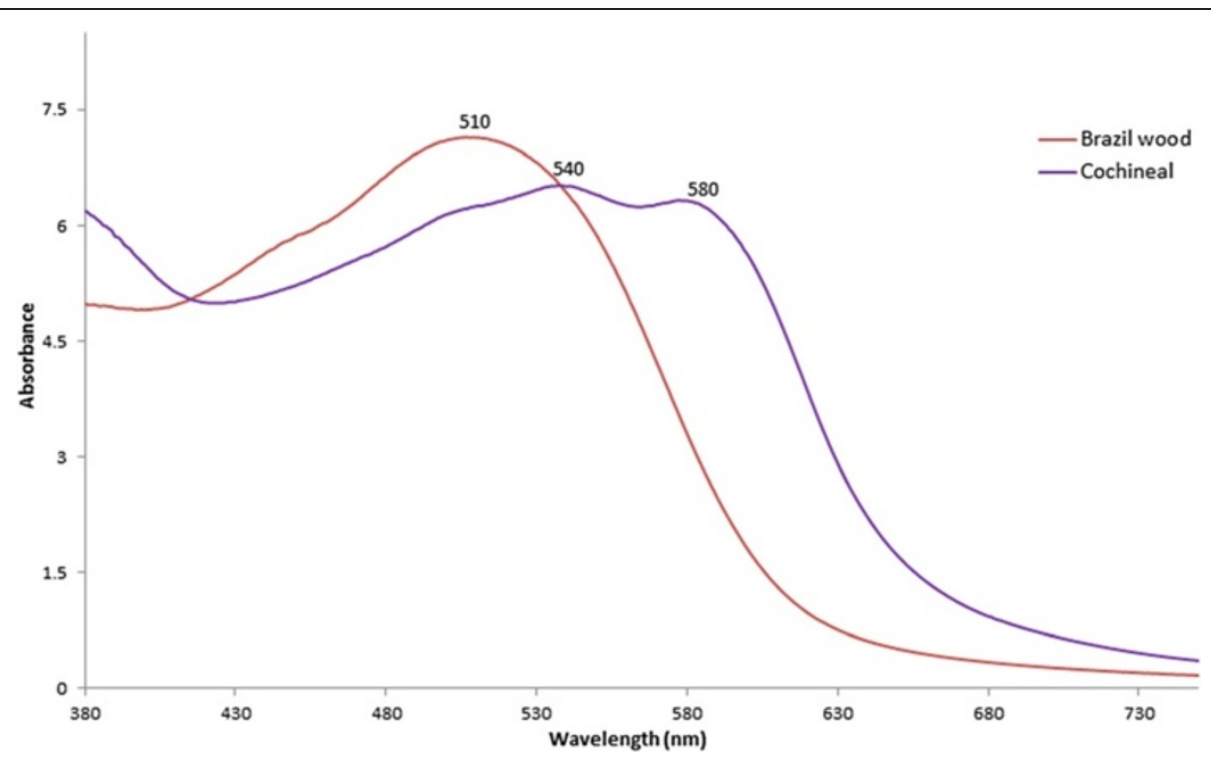

Figure 7 Absorption spectra of brazil wood and cochineal on powders.

the IRFC image of the reference pigments with those of the illumination allows us to hypothesize about the nature of the pigments used in the painting. For example, the pigment that appears yellow in IRFC is cinnabar, as in the red dress of Saint-Peter and the halo of the angel. The dark blue of the capital letter $U$ is composed of lapis-lazuli (Figure 8, right).
The advantage of this technique is the collection of a reflectance spectrum in each pixel of the image. These spectra are used for the identification of the pigments if a database of reflectance spectra with reference pigments is constituted. To simplify, on red pigments, as we have seen before by FORS, the shape of the spectra and the inflection points of the different pigments are characteristic of

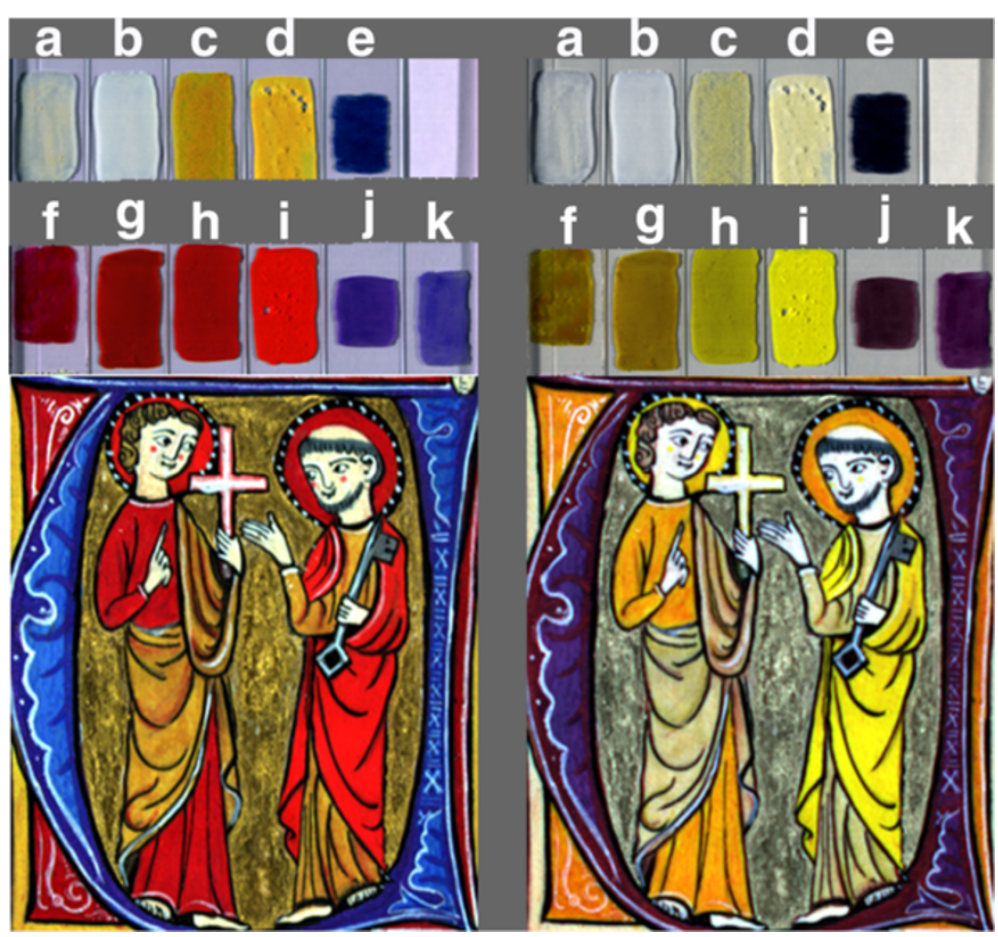

Figure 8 RGB (left) and IRFC (right) images of pigments and of the Marlier facsimile miniature. Pigments are calcite (a), lead white (b), orpiment (c), lead tin yellow (type II) (d), azurite (e), cochineal (f), red ochre (g), red lead (h), cinnabar (i), lapis-lazuli (j), Egyptian blue (k). 
their nature. The comparison of spectra permits a mapping of the different pigments on the painting. Figure 9 is an example of assigning pigments references to the painting from the reflectance spectra. The software assigns a color code (named classification) to each pigment identified on the image (for instance, dark red is associated with cinnabar, orange with orpiment and bright red with cochineal deposited on cinnabar).

Another possibility for the treatment of the data is to perform a Principal Component Analysis (PCA) giving a representation on a plane (two axes) of the collected spectra (Figure 10). In fact, HSI generates a considerable amount of data. One of the difficulties is the problem of visualizing data that has many variables. The problem can be simplified by replacing a group of variables with a single new variable. PCA is a data-processing technique for taking high-dimensional data, using the dependencies between the variables to represent it in a more tractable, lower-dimensional form, without losing too much information. PCA seeks the linear combinations of the original variables in such a way that the derived variables capture maximal variance. The method generates a new set of variables, called principal components. Each principal component is a linear combination of the original variables. All the principal components are orthogonal to each other, so there is no redundant information. The principal components as a whole form an orthogonal basis for the space

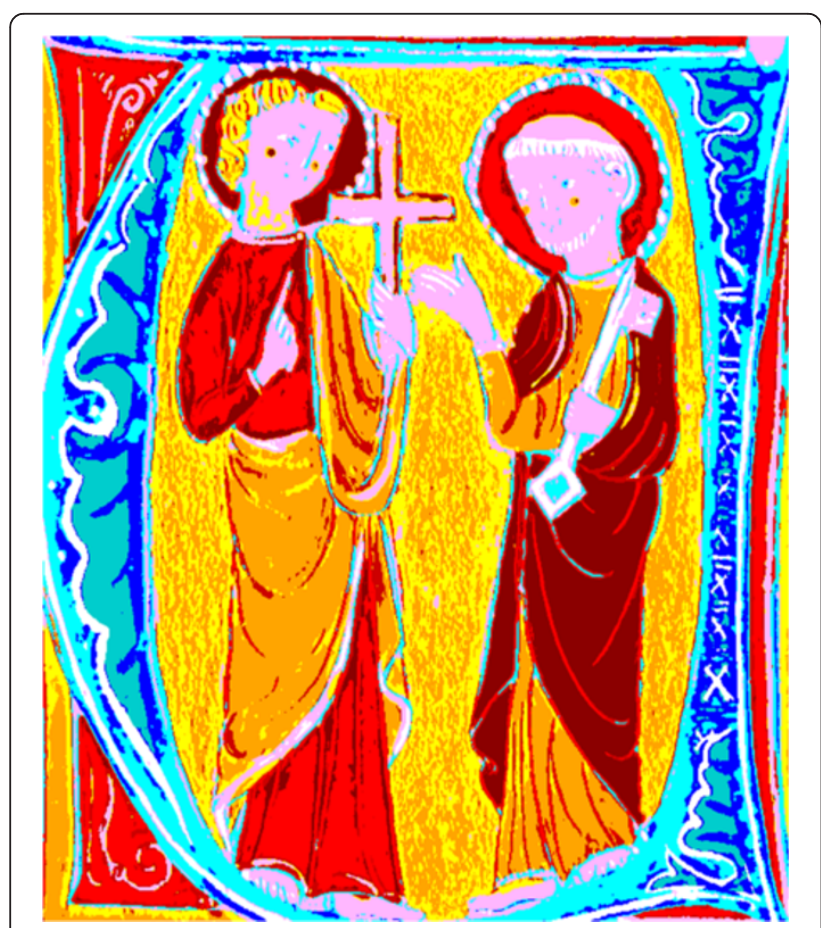

Figure 9 Mapping (classification) of the pigments based on spectra comparison: dark blue color corresponds to "azurite", turquoise blue to "lapis lazuli", dark red to "cinnabar", bright red to "cochineal on cinnabar", dark yellow to "orpiment" and pale pink to "white lead". of the data. PCA obtained can be considered as a spectral signature of the painting. It is specific to each miniature. Even if the visual appearance of two illuminations (RGB image) seems close, the PCA representation can be different if the nature of the pigments is different.

This technique allows the mapping of the different pigments, through imagery and without sampling. It's a good technique along with FORS, XRF and UV fluorescence to identify painting materials.

\section{Hyperspectral imaging under UV light}

The facsimile of a painting was also scanned with hyperspectral camera under UV light to observe the fluorescence and try to identify the pigments and/or binders.

For red pigments analyzes conducted by spectrofluorimetry allowed, the definition of the wavelength of the maximum emission fluorescence of each. Once the image acquisition under UV is completed, a wavelength can be selected and a mapping of the pigment that you want to locate on the illumination is done. For example, an experiment conducted on cinnabar shows that the fluorescence of pigments has a weak intensity, the image corresponding to the emission at $610 \mathrm{~nm}$ of the cinnabar defined by spectrofluorimetry, yields little contrast.

False color ultraviolet was done to allow a better observation of this emission of cinnabar which is present on the dresses and halos of the two characters. For this, three bands were chosen $(R \rightarrow 590 \mathrm{~nm}, \mathrm{G} \rightarrow 610 \mathrm{~nm}, \mathrm{~B} \rightarrow$ $800 \mathrm{~nm}$ ), a setting which strongly highlights the emission at $610 \mathrm{~nm}$. What appears green is cinnabar (Figure 11).

The spectrofluorimetric study was essential to select the right wavelengths for mapping the pigment that only fluoresces at $610 \mathrm{~nm}$, for example. HSI under UV light is another way to identify and map the materials used in illumination.

\section{Conclusion}

The methodological development of these techniques as well as preliminary tests on miniatures recreated according to medieval recipes and materials, allowed the validation of the analytical parameters and the creation of a database of reference spectra (parchments, pigments, binders).

Hyperspectral imaging allows the study of the entire image and offers a lot of ways to work: comparison of spectra, mapping, principal component analysis and false color images. Hyperspectral imagery was approved to its application to fragile paintings, without damage and could be applied on many Cultural Heritage objects for imagery and identification of materials. However, for a pertinent selection of the parameters to be used with the hyperspectral system, a preliminary database and study of materials under UV and visible light is needed. Two techniques are needed for the constitution of this database: FORS to 


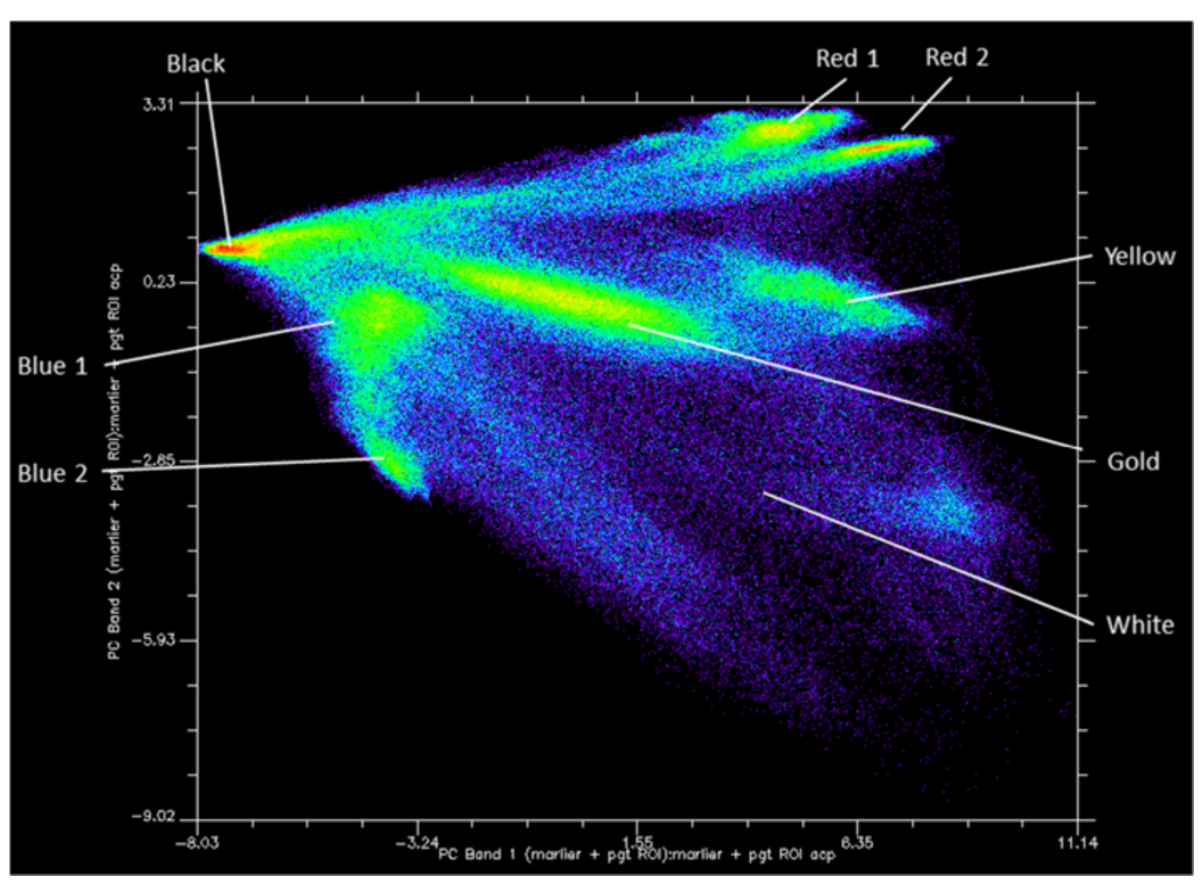

Figure 10 PCA showing the distribution of the pigments present in the illumination.

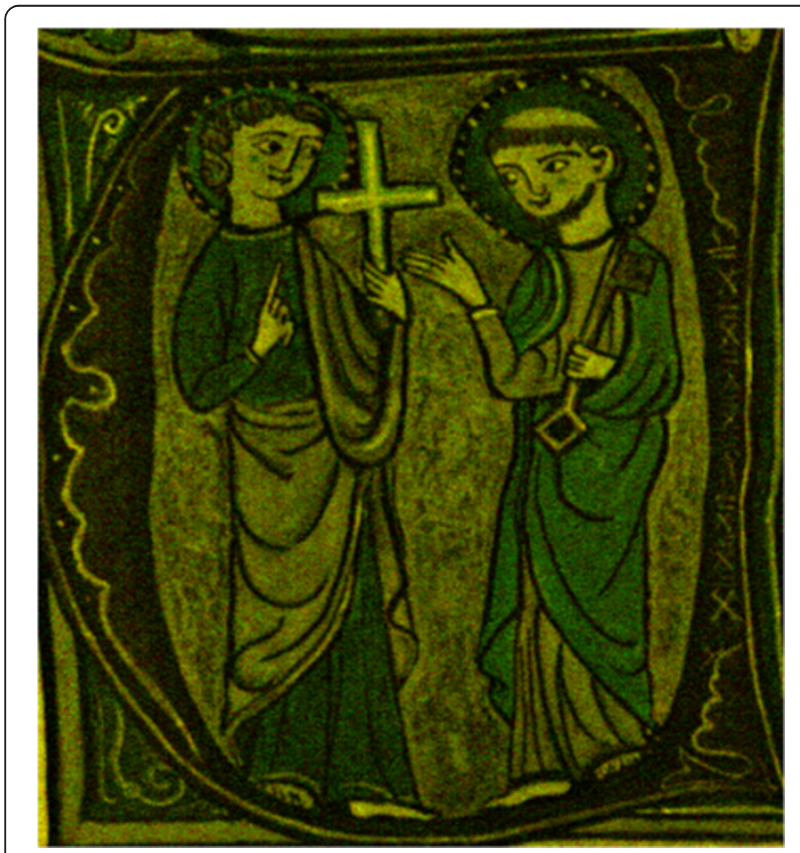

Figure 11 UV False color of the facsimile at $610 \mathrm{~nm}$ $(\mathrm{R}=590 \mathrm{~nm}, \mathrm{G}=\mathbf{6 1 0} \mathrm{nm} \& \mathrm{~B}=\mathbf{8 0 0} \mathrm{nm})$. Thanks to spectrofluorimetric study, the imagery under UV obtained with the hyperspectral camera allows us to map the cinnabar which emits fluorescence at $610 \mathrm{~nm}$. analyze reflectance spectra under halogen light; and spectrofluorimetry under UV light.

Spectrofluorimetry has proven to be an effective identification technique for the red pigments and for organic binders as regard the emission and excitation spectra.

Fluorimetric analysis and reflection spectrometry are prerequisites and necessary complements to hyperspectral imaging in order to select the best wavelengths function to be used.

These methods were compared with X-ray fluorescence spectrometry for the qualitative analysis and mapping of the inorganic elements in a facsimile purposely reproduced by an illumination painter who worked with original medieval recipes for the sake of developing the present study. XRF is required to confirm results obtain with both fluorimetry and hyperspectral imagery techniques. The novelty of this study is the application of HSI and fluorimetry and the use of the maximum wavelength obtain with the emission spectra to select one band with the HSI for mapping pigments on the painting. Consequently, the mapping obtained by XRF and the HSI are very complementary and present all the criteria of choice for applications on fragile works of the cultural heritage.

This first step study allows us to develop the methodology and the techniques. The study of the Marcadé collection may be considered through the combination of these three methods and with the help of Raman spectroscopy which has proven its worth in this field of study. 


\section{Endnotes}

${ }^{a}$ Coordinated by Floréal Daniel (IRAMAT-CRPAA), supported by the Aquitaine region, University of Bordeaux -Montaigne and the Labex LaScArBx.

${ }^{\mathrm{b}}$ The illumination is dated from the XIV century; it is a storied letter " $U$ " representing the apostle Peter accepting the cross of martyrdom from an angel. This is a Dominican antiphonal (Municipal Library of Colmar, in the coast cod. 311, fol.123). The parchment comes from Lieutard Ets and measures $15 \mathrm{~cm} \times 15 \mathrm{~cm}$ ).

\section{Competing interests}

The authors declared that they have no competing interests.

\section{Authors' contributions}

AM prepares samples and models; performs analyses and interprets results of $\mathrm{HSI}$, FORS, XRF and Spectrofluorimetry with the help of $Y L, G L B$ and CA; is the lead author of the article. GLB and CA performed spectrofluorimetric analyses and GLB helps for writing the spectrofluorimetric and absorption results. CB, SL and LS participated to the project and gave their help for the data interpretation for spectrofluorimetry and absorption analyses. $Y L$ is responsible for the XRF analyses. FD is the coordinator of the project and helps for the interpretation of results, preparation and corrections of this paper. All authors read and approved the final manuscript.

\section{Acknowledgements}

This study is part of a project supported by the Aquitaine region (France), University of Bordeaux, CNRS and the LaScArBx Cluster of excellence. We thank the cultural institutions of the Direction Régionale des Affaires Culturelles for their support and for providing access to the Marcadé collection of manuscripts and Charlotte Denoël, curator at the National Library of France. Thanks are also given to Lydie Bourgeois and Alexandre Fargues for the absorption measurements (ICMCB, Institute for Condensed Matter Chemistry of Bordeaux).

\section{Author details}

'IRAMAT - CRPAA, Institut de Recherche sur les Archéomatériaux, UMR CNRS 5060, Centre de Recherche en Physique Appliquée à l'Archéologie, Université de Bordeaux 3, Maison de l'archéologie, Esplanade des Antilles, 33607 Pessac, France. ${ }^{2}$ ISM, Institut des Sciences Moléculaires, CNRS/Université Bordeaux - UMR 5255 - Bâtiment A12, 351 Cours de la Libération, 33405 Talence, Cedex, France.

Received: 1 April 2014 Accepted: 18 October 2014

Published online: 24 October 2014

\section{References}

1. Delaney JK, Zeibel JG, Thoury M, Littleton R, Palmer M, Morales KM, de la Rie ER, Hoenigswald A: Visible and infrared imaging spectroscopy of Picasso's Harlequin Musician: mapping and identification of artists materials in situ. App/ Spectrosc 2010, 64(6):584-594.

2. Comelli D, Nevin A, Valentini G, Osticioli I, Castellucci EM, Toniolo L, Gulotta D, Cubeddu R: Insights into Masolino's wall paintings in Castiglione Olona: advanced reflectance and fluorescence imaging analysis. J Cult Herit 2011, 12:11-18.

3. Cosentino A: Identification of pigments by multispectral imaging; a flowchart method. Herit Sci 2014, 2:8.

4. Coupry C: A la recherche des pigments. In Revista de Historia da Arte, série W, N%: 2011:127-136.

5. Bicchieri M, Monti M, Piantaida G, Sodo A: Illuminations: secrets, alchemy and conservation in three case studies. In Revista de historia da Arte, série W, Nº; 2011:175-181.

6. Aceto M, Agostino A, Gulmini M, Pellizi E, Bianca V: A protocol for non-invasive analysis of miniature paintings. In Revista de Historia da Arte, série $W, N^{\circ} 1 ; 2011: 231-241$.

7. Aceto M, Agostino A, Fenoglio G, Baraldi P, Zannini P, Hofmann C, Gamillscheg E: First analytical evidences of precious colourants on Mediterranean illuminated manuscripts. Spectrochim Acta A Mol Biomol Spectrosc 2012, 95:235-245
8. Aceto M, Agostino A, Fenoglio G, Idone A, Gulmini M, Picollo M, Ricciardi P, Delaney JK: Characterization of colourants on illuminated manuscripts by portable fibre optic UV-visible-NIR reflectance spectrophotometry. Anal Meth 2014, 6:1488-1500.

9. Picollo M, Aldrovandi A, Migliori A, Giacomelli S, Scudieri M: Non-invasive XRF and UV-VIS-NIR reflectance spectroscopic analysis of materials used by Beato Angelico in the manuscript graduate $N^{\circ} 558$. In Revista de Historia da Arte, série W, No\%; 2011:219-227.

10. Ricciardi $P$, Delaney JK: Combining visible and infrared imaging spectroscopy with site specific, in-situ techniques for material identification and mapping. In Revista de historia da arte, série W, Nº; 2011:253-261.

11. Guineau B: Applications de la spectrométrie (rayons X, Infra Rouge, Raman) à la mise en évidence de lazurite et de bleu de Prusse dans des poudres minérales, Actes des 3e rencontres internationales d'archéologie et d'histoire d'Antibes, ed. A.P.D.C.A, Valbonne; 1983:75-90.

12. Cui SW, Philips GO, Blackwell B, Nikiforuk J: Characterization and properties of acacoa Senegal (L.) Willd. Var. senegal with enhanced properties (Acacia (sen) SUPERGUMTM): Part 4. Spectroscopic characterization of Acacia senegal var. senegal and Acacia (sen) SUPERGUMTM arabic. Food Hydrocolloids 2007, 21:347-352.

13. Bruni S, Cariati F, Casadion F, Toniolo L: Identification of pigments on a $\mathrm{XV}$ century illuminated parchment by Raman and FTIR microspectroscopies. Spectromchim Acta A 1999, 55:1371-1377.

14. Mannucci E, Pastorelli R, Zerbi G, Bottani CE, Faccini A: Recovery of ancient parchment: characterization by vibrational spectroscopy. J Raman Spectrosc 2000, 31:1089-1097.

15. Théophile (Moine): XII S., réédité en 1996, Essais sur divers arts, publié par le Cte Charles de l'Escalopier. Nogent Le Roi: Réédition Laget; 39-44.

16. Cennini C, XIVe, réédité en 1991: /l libro dell'arte. Paris: Berger-Levrault; 188-313.

17. Anonymous, XIVe s: De Arte illuminandi (L'Art de l'enluminure), traduit par Louis Dimier, Ed. Paris: Louis Rouard et fils; 1927.

18. Niederhauser M: Alchimie de l'enluminure, 80 recettes éprouvées. Paris: Eyrolles éditions; 2011:126.

19. Anonymous, XVII century: Manuscrit de Padoue. In Original Treatises on the Arts of Paintings of Mary Merrifield, Londres, 1849, reedited by Dover; 1967. $702 \$ 116$.

20. Le Bègue J: XV century, in Experimenta de Coloribus, traduction and publication in "Original Treatises on the Arts of Painting" de M. Merrifield, reedited by Dover; 1967

21. Carden ML: Use of ultraviolet light as an aid to pigment identification. APT Bull 1991, 23:26-37.

22. Claro A, Melo MJ, Schäfer S, Seixas de Melo JS, Pina F, Jan van den Berg K, Burnstock $A$ : The use of microspectrofluorimetry for the characterization of lake pigments. Talanta 2008, 74:922-929.

23. Larson L, Shin K, Zink J: Photoluminescence spectroscopy of natural resins and organic binding media of paintings. J Am Inst Conserv 1991 30(1):89-104.

24. Karoui R, Kemps B, Bamelis F, De Ketelaere B, Merten K, Schoonheydt R, Decuypere E, De Baerdemaeker J: Development of a rapid method based on front-face fluorescence spectroscopy for the monitoring of egg freshness: 1-evolution of thick and thin egg albumens. Eur Food Res Technol 2006, 223:303-312.

25. De la Rie ER: Fluorescence of paint and varnish layers (part I). Studies in Conservation, 27, 1-7; (part II). Studies in Conservation, 27, 65-69; (part III). Stud Conserv 1982, 27:102-108.

26. Mounier A, Dayet L, Belin C, Daniel F: Etude de la fluorescence des liants employés dans les dorures sur peintures murales médiévales. Archéosciences 2011, 35:19-28.

27. Mounier A, Belin C, Daniel F: Spectrofluorimetric study of the ageing of mixtions used in the gildings of medieval wall paintings. Environ $\mathrm{SCi}$ Pollut Res 2011, 18(5):772-782.

28. Renard D, Lavenant-Gourgeon L, Ralet MC, Sanchez C: Acacia senegal Gum: continuum of molecular species differing by their protein to sugar ratio, molecular weight, and charges. Biomacromolecules 2006, 7:2637-2649.

29. Machiels $D$, Istasse L: La réaction Maillard: importance et applications en chimie des aliments. Ann Med Vet 2002, 146(6):347-352.

30. Matteini P, Camaiti M, Agati G, Baldo M-A, Muto S, Matteini M: Discrimination of paintings binders subjected to photo-ageing by using microspectrofluorometry coupled with deconvolution analysis. J Cult Herit 2009, 10(N²):198-205

31. Brambilla L, Riedo C, Baraldi C, Nevin A, Gamberini MC, D'Andrea C, Chiantore O, Goidanish S, Toniolo L: Characterization of fresh and aged 
natural ingredients used in historical ointments by molecular spectroscopic techniques: IR, Raman and fluorescence. Anal Bioanal Chem 2011, 401:1827-1837.

32. Nevin A, Cather S, Anglos D, Fotakis C: Analysis of protein-based binding media found in paintings using laser induced fluorescence spectroscopy. Anal Chim Acta 2006, 573-574:341-346.

33. Nevin A, Anglos D, Cather S, Burnstock A: The influence of visible light and inorganic pigments on fluorescence excitation emission spectra of egg-, casein- and collagen-based painting media. Appl Phys A Mater Sci Process 2008, 92(5):69-76.

34. Gaspard S, Oujja M, Moreno P, Méndez C, Garcia A, Domingo C, Castillejo M: Interaction of femtosecond laser pulses with tempera paints. App/ Surf Sci 2008, 255(5):2675-2681.

35. Oujja M, Pouli P, Domingo C, Fotakis C, Castillejo M: Analytical spectroscopic investigation of wavelength and pulse duration effects on laser induced changes of egg-yolk based tempera paints. App/ Spectrosc 2010, 64:528-536.

36. Oujja M, García A, Romero C, R. Vázquez de Aldana J, Moreno P, Castillejo M: UV laser removal of varnish on tempera paints with nanosecond and femtosecond pulses. Phys Chem Chem Phys 2011, 13:4625-4631.

37. Oujja M, Sanz M, Rebollar E, Marco JF, Domingo C, Pouli P, Kogou S, Fotakis C, Castillejo M: Wavelength and pulse duration effects on laser induced changes on raw pigments used in paintings. Spectrochim Acta A 2013, 102:7-14.

38. Stathopoulou K, Valianou L, Skaltsounis AL, Karapanagiotis I, Magiatis P: Structure elucidation and chromatographic identification of anthraquinone components of cochineal (Dactylopius coccus) detected in historical objects. Anal Chim Acta 2013, 804:264-272.

39. Lang PL, Orna MV, Richwine LJ, Mathews TF, Nelson RS: The visible and infrared microspectroscopic characterization of organic red pigments removed from three medieval byzantine manuscripts. Microchem J 1992, 46:234-248.

40. Miliani C, Romani A, Favaro G: Acidichromatic effects in 1.2-di- and 1,2,4tri-hydroxyanthraquinones: a spectrophotometric and fluorimetric study. J Phys Organ Chem 2000, 13:141-150.

41. Casini A, Loti F, Picollo M, Stefani L, Aldrovandi A: Fourier transform interferometric imaging spectrometry: a new tool for the study of reflectance \& fluorescence of polychrome surfaces. Conserv Sci 2002, $38: 248-252$

doi:10.1186/s40494-014-0024-z

Cite this article as: Mounier et al:: Hyperspectral imaging, spectrofluorimetry, FORS and XRF for the non-invasive study of medieval miniatures materials. Heritage Science 2014 2:24.

\section{Publish with ChemistryCentral and every scientist can read your work free of charge \\ "Open access provides opportunities to our colleagues in other parts of the globe, by allowing anyone to view the content free of charge." \\ W. Jeffery Hurst, The Hershey Company.}

- available free of charge to the entire scientific community

- peer reviewed and published immediately upon acceptance

- cited in PubMed and archived on PubMed Central

- yours - you keep the copyright

Submit your manuscript here:

http://www.chemistrycentral.com/manuscript/<smiles>c1ccccc1</smiles>

ChemistryCentral 